\title{
Analysis of the Health Care Delivery System in Pakistan and Nepal
}

\author{
Mishal Liaqat \\ MS. Nursing Student, University of Lahore, Pakistan \\ Muhammad Hussain \\ Assistant Professor, University of Lahore, Pakistan \\ Iram Liaqat* \\ Associate Professor, Microbiology Lab, Department of Zoology \\ G. C. University, Lahore, Pakistan
}

\begin{abstract}
The health care delivery system (HCDS) of a country plays a significant contribution to its development. The provision of effective, efficient, and quality health services leading to decreasing morbidity and mortality rate across the country. Primarily, these services are provided to promote, protect and maintain the health of every individual and enable them to take an active role in country development. Health is now a global issue and HCDS and its challenges are varies from country to country. Analysis of HCDS is important to determine its key resources, challenges and effective utilization of these resources. Here, we analyze HCDS of Pakistan in contrast to Nepal with aspects of health services, financing, health workforce, medical products and technologies, information, service delivery and give some recommendations at the end that address the key problems in the systems.
\end{abstract}

Keywords: HCDS, Pakistan, Nepal, Health workforce

DOI: $10.7176 / \mathrm{JMPB} / 62-02$

Publication date: December $31^{\text {st }} 2019$

\section{Introduction to the Health Care Delivery System}

Health Care Delivery System (HCDS) is a system that provides health services to the individual, community, and population through organized efforts of people, organizations, agencies, and resources. The main purpose of HCDS is to protect, promote, restore and maintain the health of people with specific needs and values (1). Pakistan is an under-developing country and ranked in the world as the sixth most populous country. It is estimated that if its population was not controlled it will be on the fourth most populous country in 2050 (2). Pakistan has two types of government Provincial and federal. Health is basically considered as the responsibility of the provincial government. The HCDS of Pakistan is divided both horizontally and vertically. The primary health services are the major strength of HCDS of Pakistan that is distributed by lady health visitors, lady health workers, and community midwives. That provides services to the community on the doorstep (3). The four modes of provision of health services are preventive, promotive, curative and rehabilitative. Mainly health is controlled by two types of systems Public and private. Public hospitals are contributed to $25 \%$ and the rest $75 \%$ is covered by private sectors (4).

Nepal is a small country located in Himalyia between India and China. Its socioeconomic status is considered a low-income country. The country is facing the transition from a unitary state to a federalized system for changing and adopting new roles of the local, provincial and federal government. According to its constitution article 35 , every citizen has the right to access free health care services and should be provided emergency care and a clean environment. Now there are free of cost services is provided at Sub-Health Post, Health Post, and Primary Health Care Centre and at District Hospital (5). The article 35 also recognizes women's right to reproduction and the accessibility to safe delivery service. The provision of health services is under local government while federal will make policies, plan and annual budget for health. As a signatory on Alma-Atta declaration in 1978 goal of Health for All was not achieved but really close to the goal of MDGs, 2015 (6). The basic focus of the government is in the provision of curative services rather than preventive and promotive services. Almost 5\% of the total budget is allocated for health in which a major portion is expended on the hospital's development (7).

\section{Health Care Indicators}

In Pakistan despite social, economic, political and natural disasters still, there is a progressive improvement in health care indicators in the last 25 years. This change is contributed by various public, private, national and international organizations but still, there is a lot of need for improvement (8). According to a report of the Ministry of Finance life expectancy of Pakistan is 59 years in 1990 and now it is 66.6 years. The mortality rate 
in infants is $69 / 1000$ live births, mortality rate in under-five is $85.5 / 1000$ children, the maternal mortality rate is $130 / 1000$ and population growth rate is $1.92 \%$ is reported (9). The neonatal mortality rate is still very high and reported as 43/1000live births (10).

In contrast, Nepal has a great improvement in its health-related indicators in the last two decades and reducing its under-five mortality rate that is 386 per 1000 live births in 2015 . It has been estimated that from the period of 1990 to 2014 it has been declined to $73 \%$. The infant mortality rate is reported as 338/1000 live births. The maternal mortality rate is too reduced considerably as it is 790/1000 in 1996 and in 2013 it is reported as 190/1000. The neonatal mortality rate is still alarming and reported as a 57\% reduction from a period of 1990 to 2014 (11). The average life expectancy is 68.4 and the population growth rate is $1.17 \%(12)$.

\section{Analysis of Both the Healthcare System}

Analysis of both Pakistan and Nepal health care delivery systems depends on the framework proposed by World Health Organization (WHO) in 2000 and based on the following components health services, financing, health workforce, medical products and technologies, information, and service delivery.

\subsection{Health Services}

Pakistan striving to improve its health services but was not achieve the standard of "Health for All" 2000 due to poor management of policies and insufficient resources. Health services are provided at three levels first is primary included basic health unit (BHU) and rural health center (RHC) at each union council. Secondary level included tehsil headquarters (THQ) and District health quarters (DHQ) at the tehsil level with nine specialties provided. The third level is tertiary care hospitals affiliated with teaching institutes and are located in big cities. The majority of the population in Pakistan is using health facilities throughout of pocket payment only $27 \%$ of the total population is using free health services and these included government servants and armed persons (13). Inadequate infrastructure of HCDS, fragmatic delivery of services, and inequitable access between urban and rural areas are the major problems in HCDS of Pakistan that make it nonresponsive.

In contrast to Nepal government strive to access the basic health services are provided to every Nepali citizen. The government provides referral and specialized services through a chain of tertiary, specialty and academic hospitals that are mostly located in urban areas all over the country. In rural areas, free access to health services is provided through the expansion of basic health packages (14). Community-based health services are provided that successfully diagnose and treat children in the community and reducing mortality in under-five year children from two major causes of pneumonia and diarrhea (15). The national immunization program in 2017 provided free vaccination through public and community outreach efforts. This causes a great reduction in childhood morbidity and mortality. However children in rural areas and those living in mountains are not receiving vaccines adequately (16).

\subsection{Financing}

Financing deals with the ways in which revenue is generated and pooled in the provision of health services. Unfortunately in Pakistan, a larger portion of revenue is not pooled due to direct out of pocket payment (17). Pakistan is a low socio-economic country and spends only $0.6 \%$ on health services. The total allocation of budget on health services is only $3.4 \%$ in which $80 \%$ is used for curative services and $20 \%$ is used only for preventive and primary health care services (18). Inadequate knowledge and poor management of resources leading to low utilization and lapse of funds. Donor financing is less than $2 \%$ in Pakistan. In which the main agencies are HANDS, Shiffa, and Aga Khan Health Services while external agencies are Department for International Development, UK and USAID work in collaboration with the government to improve the health status of the public (19).

In Nepal health is financed through government budget, donor funding and out of pocket payment. A high proportion of the budget is consumed in essential services such as education and social services (20). This leading to a decreasing budget of health that is only 3.9\% was allocated for health in the year 2016-2017 as compared to $2005-2006$ in which it is $6.3 \%$ (21). This situation leads to an increasing spread of private services. As there were only 16 private hospitals in 1990 while in 2014 their number was 301 (22). Due to lack of facilities in public hospitals, people are increasingly using private hospitals, and pharmacies and this results in high out of pocket payment in the population.

\subsection{Health Workforce}

Pakistan is one of the among 57 countries that has a severe shortage of health care workers including doctors, nurses, Auxillary staff, paramedic staff and managerial staff (23). In Pakistan Doctor to patient ratio is not sufficient and is reported as 1: 1300 and nurse to population ratio is 1: 3568 which is quite alarming (24). The major issue is the low grade of job satisfaction and fewer opportunities to upgrade knowledge that meet the public and local demands in the provision of health care services. Dual practice is common among health 
professionals that affect their interest and quality of service.

In Nepal doctor ratio to population is 0.17 per 1000 and nurse ratio to population is 0.51 per 1000 population. This indicates the quite shortage of health professionals as compared to the population. There are a lot of vacant posts along with the absenteeism of health workers. Further health workers are deficient in knowledge and skill to meet the health demands of the population due to the result of an increased number of private medical schools across the country (25). In these medical schools, only a few offer specialization. Due to lacking quality education and training many were not clear licensure examination and clearance rate is only $35 \%$ reported (26). However medical education act in 2017 again focused on quality education and training among health care providers and processes to reduce their shortage.

\subsection{Medical Products and Technologies}

In the provision of preventive, curative and rehabilitative services health care system needs many types of equipment, drug vaccines, diagnostic tool and advance machinery which is not present in many HCDS of Pakistan. The health information management system is also poor so lacking the documentation and reporting of vital statistics in the country (Ministry of Health Singapore, 2014). At the time of independence, there is no pharmaceutical company but now there is great progress and has 411 registered pharmaceutical companies and 30 are multinational that provided $80 \%$ of medicines to meet the country demand and $20 \%$ of its manufacturing are being imported. But still, there is required a great deal of improvement (27).

While in Nepal the first national drug policy was made in 1995 and updated in 2007. The main purpose of this policy was to ensure that every citizen in Nepal receives quality, safe and effective drugs at a reasonable cost. In 2006 the total number of pharmacy retail outlets was 4957 and the wholesale-retail outlet was 855 in which the majority was in the Kathmandu valley. So a big challenge was to spread them across the whole country. Currently, the country faces a shortage of equipment, resources, machinery and medicines that is a big hurdle in the achievement of the Universal Health Coverage goal (28).

\subsection{Information}

The health management and information system (HMIS) is essential for recording, maintaining and organizing data related to health. This data is further helpful in policymaking, its implementation, and evaluating the effectiveness of health-related strategies. In Pakistan HMIS is initiated in 1991 and still unable to represent a true picture of health in the country due to lacking proper reporting, management and recording (29) . HMIS of Pakistan is quite fragmented and lacking accuracy, validity, and reliability of information often the information and data collected is conflicting in results with each other. The country still in a struggle to improve HMIS in collaboration with world health organization. On the other hand, some Private sectors and armed hospitals are well equipped in infrastructure and HMIS, providing care in a much better way but covered only a limited portion of the population (30).

In Nepal, the health management information system (HMIS) is activated at all levels both in public and private sectors and plays crucial role in decision making regarding policy implementation. The major challenge faced by the HMIS of Nepal is the coherence of information with other comprehensive reporting statistics. Like other developing countries HMIS of Nepal is also poor in accuracy and reliability. There is a dire need to further develop and improve the reporting of the event through collaboration with other organizations. Improper and misleading data would influence decision making especially in such a country that already has a shortage of resources (20).

\subsection{Service Delivery}

Service delivery is fragmented both horizontally and vertically. There are 1096 public hospitals, basic health units are 5527, rural health centers are 650, and 5310 dispensaries across the country. The public hospital provides care to $30 \%$ of the total population. Private hospital is the largest care provider in the country that covers $70 \%$ of the total population. These services are provided through direct out of pocket payment and enhance the level of impoverishment of the public (31).

In Nepal after the adaptation of National health policy in 1991, there is significant progress in health services. There are three levels of service delivery. The primary health care delivery system provides care at the district level through primary health care centers, sub-health posts, and health posts. Secondary and tertiary health services are provided through regional and specialized hospitals in the zonal area. There are 89 hospitals that provided basic health services, 187 primary health care centers, 68 health posts and 3129 are sub-health posts across the country. But still, these public facilities fail to cover the whole population and privatization is largely leading service providers in the country (20).

\section{Challenges of Health Care System}

Pakistan HCDS faces a lot of social, economic, cultural and political challenges. Lack of resources, poor funding, 
corruption, and political instability are the major contributing factors that hinder its growth. Only a small portion of the budget is allocated on health annually. There is a replication of services and no proper gatekeeping or referral system at primary health care. That results in a lot of burden at tertiary hospitals and waste of resources. There is no proper reporting and documentation of malpractice incidents that affect the quality of care. There is large over the counter sale of medicines as a result of poor checking and recording (32). Unnecessary tests and medicines are prescribed due to insufficient training and knowledge. The dual practice of health professionals is common that affects their quality of services. Health inequalities are a major challenge, especially in rural areas.

On the other hand, the health care system of Nepal faces significant challenges in the provision of care including a workforce of health professionals such as doctor's nurses, paramedical staff and a lack of equipment and supplies. Health professionals are less prepared to fulfill the demand for care in providing quality and costeffective care. The human resource of Nepal consists of 35 thousand people who are unable to meet the health demands of the whole population. So, temporary hiring of medical staff and fulfilling the demand through private sectors in the provision of services (33).

The budget on health allocation is quite short as compared to need. Health inequality in rural and urban areas is another big challenge. The increasing number of disease burden due to non-communicable disease, mental health problems, and disorders due to natural disaster is another major challenge.

\section{Conclusion}

In the light of above situation it is strongly argued that both Pakistan and Nepal faces a lot of deficiencies in its health system. These deficiencies must be overcome through improvement in the present health care system. The basic purpose of which is to resolve health inequality and the provision of essential services to both in rural and urban areas. It is recommended to adopt a multi-sectorial collaborative approach to enhance the health care services. Moreover, the Health care delivery system is under the influence of multiple political, economic, social and environmental factors. The health system of Pakistan and Nepal is looking towards a political commitment to prepare, design and implement such policies that leading the country a universal health coverage of all populations.

\section{Recommendations}

The author recommends that in relation to improving the HCDS of Pakistan and Nepal several strategies are being adopted. The government of both countries should increase the health budget and deal with the allocation of resources fairly both in rural and urban areas. There should be an initiative in both countries for the quality production and development of health professionals including doctors, nurses, and other auxiliary staff according to the population ratio. All the stakeholders should involve in the planning and implementation of policies (34). There should be more strengthening of primary health services and a strong referral system should be adopted for the efficient use of services.

\section{References}

1. Mills, A.(2014). Health care systems in low-and middle-income countries. New England Journal of Medicine, $370,552-557$.

2. National Institute of Population Studies and ICF International. (2013). Pakistan Demographic and Health Survey 2012-13. National Institute of Population Studies. Islamabad. Pakistan.

3. Ghaffar, A., Kazi, B. M., \& Salman, M. D. (2000).Health care systems in transition III. Pakistan, part I. An overview of the health care system in Pakistan. Journal of public health medicine, 22, 38-42.

4. Nishtar, S. (2006). The Gateway Paper; Health System in Pakistan - a Way Forward. Pakistan's Health Policy Forum and Heart file. Islamabad, Pakistan

5. Ministry of Health and Population. (2009). Health Sector Gender Equality and Social Inclusion Strategies. Kathmandu: Ministry of Health and Population..

6. Ridde, V., Messen, B., \& Kouanda, S. (2011). Selective Free Health Care in Sub-Saharan Africa: An opportunity for Strengthening Health System? Sante Publique, 23, (61-7).

7. Rana, K. (2018). Pediatric maxillofacial injuries in Madinah - a retrospective study. Journal of Public Health Policy \& Planning, 2(2), 81-83

8. Meghani, S. T., Sehar, S., Punjani, N. S. (2014). Comparison and Analysis of Health Care Delivery System: Pakistan versus China. International Journal of Endorsing Health Science Research, 2, 46-50.

9. Ministry of Health. (2017). Annual Progress Report of Health Sector Fiscal Year 2015/16. Kathmandu: Ministry of Health.

10. National Institute of Population Studies \& Macro International. (2014). Pakistan Demographic \& Health Survey 2012-13. Islamabad.

11. Ministry of Health and Population, (2015). Government of Nepal. Nepal Health Sector Strategy, 2015-2020. Government of Nepal: Saugat Printing and Publication. 
12. National Institute of Population Studies \& Macro International. (2014). Pakistan Demographic \& Health Survey 2012-13. Islamabad.

13. Hassan, A., Mahmood, M., Bukhsh, H. A. (2017). Healthcare System of Pakistan. International Journal of Advanced Research and Publications, 1(4).

14. Ministry of Health. (2016). Nepal Demographic Health Survey - KI. 2016. Kathmandu: Ministry of Health

15. Department of Health Services. (2016). Annual Report 72/73. Kathmandu: Ministry of Health.

16. Ministry of Health. (2016). Bopanna Nagarik Aushadhi Upachaar Kosh Nirdeshika (Second Amendment), 2073. Kathmandu: Ministry of Health.

17. Islam, A. (2009). Bangladesh health system in transition: selected articles. James P. Grant School of Public Health. BRAC University.

18. Shaikh, B., Rabbani, F., Safi, N., \& Dawar, Z. (2010). Contracting of primary health care services in Pakistan: is up-scaling pragmatic thinking. Journal of the Pakistan Medical Association, 60(5), 387-389.

19. Ather, F., \& Sherin, A. (2014). Health System Financing in Pakistan: Reviewing Resources and opportunities. Khyber Medical University Journal, 6, 53-55.

20. World Health Organization. (2017). World Health Statistics 2017. Geneva.

21. Ministry of Health. (2017). National Health Accounts 2011-12. Kathmandu: Ministry of Health.

22. Central Bureau of Statistics. (2013). Census of Private Hospitals. Kathmandu: Central Bureau of Statistics.

23. Rana, S. A., Sarfraz, M., Kamran, I., \& Jadoon, H. (2016). Preferences of doctors for working in rural Islamabad capital territory, Pakistan: a qualitative study. Journal of Ayub Medical College Abbottabad, 28, 591-596.

24. Pakistan Medical Student. (2013). Nursing shortage in Pakistan-Human resource management in the health system. Journal of Pioneering Medical Sciences.

25. World Health Organization. (2016). Global Strategy on Human Resources on Health: Workforce 2030. Geneva.

26. Nepal Medical Council. (2017). Recognized Institutions - Medical College. Nepal Medical College.

27. Ministry of Health Singapore. (2014). Health manpower. Available https:/www.moh.gov.sg/content/moh_web/home/statistics/Health_Facts_Singapore/ Health_Manpower.html

28. Pokharel, R., \& Silwal, P. R. (2018). Social health insurance in Nepal: A health system departure toward universal health coverage. International Journal of Health Planning \& Management.

29. Qazi, M. S., \& Ali, M. (2009). Pakistan's health management information system: health managers' perspectives. The Journal of the Pakistan Medical Association, 59(1), 10-14.

30. Punjani, N. S., Shams, S., \& Bhanji, S. M. (2014). Analysis of health care delivery systems: Pakistan versus the United States. International Journal of Endorsing Health Sciences, 2: 38-41.

31. Aslam, L., Abdullah, A., \& Ayub, R. (2014). Analysis of Pakistan and Iran Health Care Delivery System. International Journal of Innovative Research and Development, 3(7), 308-312.

32. Shaikh, B. T., Ejaz, I., Achakzai, D. K., \& Shafi, Q.Y. (2012). Political and economic unfairness in the health system of Pakistan: a hope with the recent reforms. Journal of Ayub Medical College, 25(1- 2), 198203.

33. Thapa, R., Bam, K., Tiwari, P., Sinha, T. K., \& Dahal, S. (2019). Implementing Federalism in the Health System of Nepal: Opportunities and Challenges. International journal of health policy and management, 8(4), 195-198.

34. Kumar, S., \& Bano, S.(2017). Comparison and Analysis of Health Care Delivery Systems: Pakistan versus Bangladesh. Journal of Hospital Medicine Management, 3:1. 